\title{
Erratum to: World Congress on Osteoporosis, Osteoarthritis and Musculoskeletal Diseases (WCO-IOF-ESCEO 2016): Poster Abstracts
}

\author{
Springer London
}

Published online: 5 February 2018

(C) International Osteoporosis Foundation and National Osteoporosis Foundation 2018

\section{Erratum to: Osteoporos Int}

DOI: 10.1007/s00198-016-3530-x

An error occurred in the authorship of abstract P818 (Awareness of Osteoporosis Among Iranian Female Head of Household) of the article "World Congress on Osteoporosis, Osteoarthritis and Musculoskeletal Diseases (WCO-IOFESCEO 2016): Poster Abstracts", published in volume 27, supplement 1 of Osteoporosis International. The correct authorship is as follows:

Pouria Khashayar ${ }^{1}$, A. Ziaee ${ }^{1}$, Patricia Khashayar ${ }^{2}$, A. Keshtkar $^{3}$, B. Larijani ${ }^{4}$

${ }^{1}$ Qazvin University Of Medical Sciences, Qazvin, Islamic Republic of Iran; ${ }^{2} \mathrm{Orc} / \mathrm{EMRI} / \mathrm{TUMS}-\mathrm{CMST}$, University of Gent, Gent, Belgium; ${ }^{3}$ Tehran University of Medical Sciences, Tehran, Islamic Republic of Iran; ${ }^{4}$ Endocrinology and Metabolism Research Center, Dr. Shariati Hospital, Tehran University of Medical Sciences, Tehran, Islamic Republic of Iran

The online version of the original article can be found at https://oi.org/ 10.1007/s00198-016-3530-x

Springer London

Springer-Verlag London Ltd, 236 Gray's Inn Road, London,

WC1X 8HB, United Kingdom 